\begin{tabular}{|c|c|}
\hline Title & Organic nanodots of a cation radical salt of amphiphilic bis TTF annulated macrocycle \\
\hline Author(s) & A kutagawa, Tomoyuki; Nakamura, Takay oshi; Becher, Jan \\
\hline Citation & $\begin{array}{l}\text { Molecular Crystals and Liquid Crystals, 455(1), 71-74 } \\
\text { https://doi.org/10.1080/15421400600697891 }\end{array}$ \\
\hline Issue Date & 2006-10 \\
\hline Doc URL & http:/hdl.handle.net/2115/30231 \\
\hline Rights & $\begin{array}{l}\text { This is an electronic version of an article published in A kutagawa, T; Nakamura, T; Becher, J, Organic nanodots of a } \\
\text { cation radical salt of amphiphilic bis TTF annulated macrocycle, MOLLCULA R CRY STALS AND LIQUID } \\
\text { CRY STALS, 455(1), Oct 2006, pp.71-74. MOLECULAR CRY STALS A ND LIQUID CRY STA LS is available online } \\
\text { at: http:/Www.informaworld.com/ }\end{array}$ \\
\hline Type & article (author version) \\
\hline File Information & MCLC455.pdf \\
\hline
\end{tabular}

Instructions for use 


\title{
Organic Nanodots of a Cation Radical Salt of Amphiphilic Bis-TTF Annulated
}

\section{Macrocycle}

\author{
Tomoyuki Akutagawa* and Takayoshi Nakamura* \\ Research Institute for Electronic Science, Hokkaido University, \\ N12W6 Kita-ku Sapporo, Hokkaido 060-0812, Japan \\ Jan Becher \\ Department of Chemistry, University of Southern Denmark, \\ Campusvej 55, DK-5230, Denmark
}

* Corresponding author. E-mail: takuta@imd.es.hokudai.ac.jp

Keywords: $\quad$ organic nanodots; charge-transfer; spin-coat films; TTF; nanostructures 


\begin{abstract}
Organic nanodots of a cation radical salt of amphiphilic bis-TTF annulated macrocycle derivative were fabricated on mica surface by cast technique. The nanodots, whose diameter and height of nanodots depended on the surface positions, were arranged on mica surface during the solvent evaporation process.
\end{abstract}

\title{
INTRODUCTION
}

A variety of crystalline molecular conductors have been developed after the discovery of a highly conducting organic semiconductor. ${ }^{1,2}$ Nanostructures of these molecular conductors have a potential to form novel electrically conducting nanomaterials. Electrically conducting Langmuir-Blodgett films are one of such examples. ${ }^{3}$ Although the film thickness of a LB film is controllable at the order of molecular scale along the film-normal direction, the control of in-plane structures at the substrate surface is usually difficult.

We have constructed molecular-assembly nanowires based on a charge-transfer (CT) complex of amphiphilic bis-tetrathiafulvalene (bis-TTF) annulated macrocycle as an example of electrically conducting nanostructure. ${ }^{4-6}$ Furthermore, size-controllable nanodots of a cation radical salt of ethylenedithio-substituted bis-TTF annulated macrocycle derivative (1 in Scheme 1) were successfully fabricated on substrate surface by using spin-coating technique. ${ }^{7}$ When a $0.5 \mathrm{mM} \mathrm{CHCl}_{3}: \mathrm{CH}_{3} \mathrm{CN}(8: 2)$ solution of $\mathbf{1}-\left(\mathrm{I}_{2}\right)_{2}$ was subjected to form spin-coat films, the diameter of nanodots was controllable in the diameter range from 20 to $1000 \mathrm{~nm}$. Here, we report cast films of $1-\left(I_{2}\right)_{2}$ on mica surface, which formed novel nanostructures depended on evaporation process of solvent. 


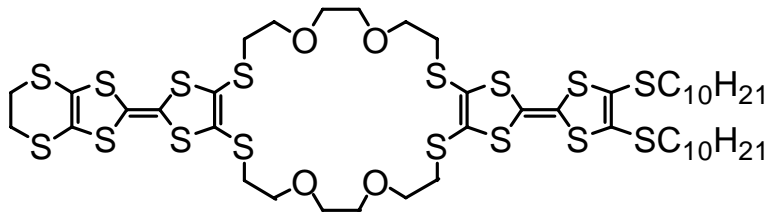

\section{1}

Scheme 1. Molecular structure of ethylenedithio-substituted bis-TTF annulated macrocycle $\mathbf{1 .}$

\section{EXPERIMENTAL}

Cation radical of the $\mathbf{1}-\left(\mathrm{I}_{2}\right)_{2}$ was prepared in situ by mixing $\mathbf{1}$ and two equivalents of $\mathrm{I}_{2}$ in $\mathrm{CHCl}_{3}: \mathrm{CH}_{3} \mathrm{CN}(\mathrm{v} / \mathrm{v}=8: 2)$. Concentration of the solution was fixed at $0.5 \mathrm{mM}$ with respect to $\mathbf{1}-\left(\mathrm{I}_{2}\right)_{2}$. The casted-films were fabricated by dropping a solution at the one end of a freshly cleaved mica substrate. Then the substrate was tilted about 15 degree to allow smooth flow of the solution from upper (top) and lower (bottom) surface of mica.

Dynamic mode AFM images were taken using a Seiko SPA 400 with an SPI 3800 probe station. Commercially available Si cantilevers with a force constant of $13 \mathrm{~N}$ $\mathrm{m}^{-1}$ were used.

\section{RESULTS AND DISCUSSION}

Electron donating ability of molecule $\mathbf{1}$ enabled us to apply chemical oxidation by dissolving two equivalent of iodine molecule $\left(\mathrm{I}_{2}\right)$ into a $0.5 \mathrm{mM}$ solution of $\mathbf{1}$ in $\mathrm{CHCl}_{3}: \mathrm{CH}_{3} \mathrm{CN}(\mathrm{v} / \mathrm{v}=8: 2)$. The oxidized 1 have an open-shell electronic structure and 
should form cation radical salt with $\mathrm{I}^{-}$or $\mathrm{I}_{3}^{-}$. The solution of $\mathbf{1}-\left(\mathrm{I}_{2}\right)_{2}$ was utilized to form casted-films on freshly cleaved mica. Formations of nanodots were confirmed in the cast-films (Fig. 1), which was similar to those of spin-coat films. ${ }^{7}$ However, the nanodots showed different surface morphologies from the top to bottom area of the mica. Since we tilted the mica surface about 15 degree, a flow of the solution from top to bottom direction generated the surface morphology change. The nanodots on bottom area were almost isolated to each other (Fig. 1a), whose average diameter and height were 600 and $40 \mathrm{~nm}$, respectively. On the other hand, the diameter and height of nanodots on top area was much smaller than those of the bottom area (Fig. 1b). The average diameter and height of nanodots on bottom area were 400 and $20 \mathrm{~nm}$, respectively. Since the nanodots were formed on mica surface by the evaporation of cation radical solution, increase of the concentration of the cation radical solution at the bottom area increased the diameter and height of nanodots.

a.

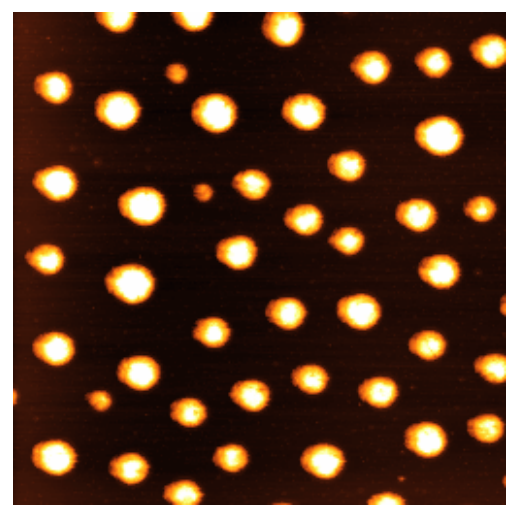

b.

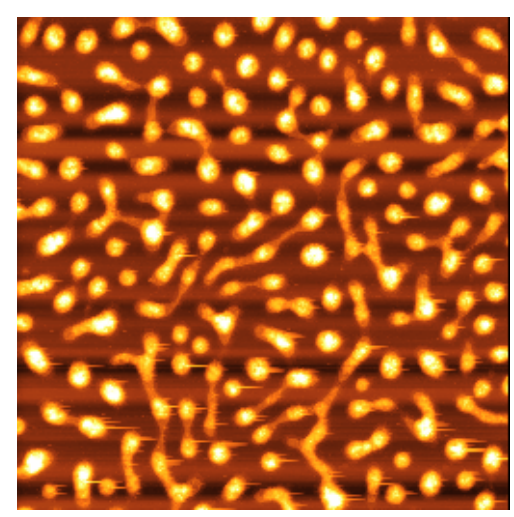

Figure 1. Nanodot structures of cast-films of $\mathbf{1}-\left(\mathrm{I}_{2}\right)_{2}$. Surface morphology of nanodots on a) bottom and b) top area of mica. The size of images are $10 \times 10 \mu \mathrm{m}$.

It should be noted that the nanodots of top area are two-dimensionally connected to each other (Fig. 1b). The network structure of nanodots has a potential to form novel 
nano devices based on semiconducting properties of nanodots. The diameter, height, and connectivity of nanodots in the cast-films clearly depended on the evaporation process of solution. The dimensionalities and connectivities of nanostructures are controllable to adjust the evaporation process and concentration of cast solution.

\section{SUMMARY}

Organic nanodots of an amphiphilic bis-TTF annulated macrocycle with open-shell electronic structure were obtained by simple cast technique. Diameter, height, and connectivity of nanodots were depended on the evaporation process of the cast solution.

\section{REFERENCES}

[1] Akamatsu, H., Inokuchi, H. \& Matsunaga, Y. Nature, 173, 168, (1954).

[2] Ishiguro, T., Yamaji, K. \& Saito, G. Organic Superconductors, Springer-Verlag: Berlin, (1998).

[3] Nakamura, T. Handbook of Organic Conductive Molecules and Polymers. Vol. 1, p. 728, Wiley: Stuttgart, (1997).

[4] Akutagawa, T., Ohta, T., Hasegawa, T., Nakamura, T., Christensen, C. A. \& Becher, J. Proc. Natl. Acad. Sci. USA, 99, 5028, (2002).

[5] Akutagawa, T., Kakiuchi, K., Hasegawa, T., Nakamura, T., Christensen, C. A. \& Becher, J. Langmuir, 20, 4187, (2004).

[6] Nakamura, T., Tatewaki, Y., Ohta, T., Wakahara, K., Akutagawa, T., Hasegawa, T., Tachibana, H., Azumi, R., Matsumoto, M., Christensen, C. A. \& Becher, J. Bull. Chem. 
Soc. Jpn., 78, 147, (2005).

[7] Akutagawa, T., Kakiuchi, K., Hasegawa, T., Noro, S., Nakamura, T., Hasegawa, H., Mashiko, S. \& Becher, J. Angew. Chem. Int. Ed. Engl. in press, (2005). 